\title{
Interleukin 10 deficiency attenuates induction of anti-TSH receptor antibodies and hyperthyroidism in a mouse Graves' model
}

\author{
Ikuko Ueki $^{1,2}$, Norio Abiru ${ }^{2}$, Kentaro Kawagoe ${ }^{1}$ and Yuji Nagayama ${ }^{1}$ \\ ${ }^{1}$ Department of Molecular Medicine, Atomic Bomb Disease Institute and ${ }^{2}$ Division of Immunology, Endocrinology and Metabolism, Department of Medical and \\ Dental Sciences, Graduate School of Biomedical Sciences, Nagasaki University, 1-12-4 Sakamoto, Nagasaki 852-8523, Japan \\ (Correspondence should be addressed to Y Nagayama; Email: nagayama@nagasaki-u.ac.jp)
}

\begin{abstract}
Experimental Graves'-like hyperthyroidism can be induced in susceptible mouse strains by repetitive immunizations with recombinant adenovirus expressing the human full-length TSH receptor (TSHR) or its A-subunit. Previous studies have shown that splenocytes from immunized mice produce interferon (IFN) $\gamma$ and interleukin (IL) 10 in response to antigen stimulation in an in vitro $\mathrm{T}$ cell recall assay. Although IFN- $\gamma$ is now well known to be essential for disease induction, the role(s) played by IL10 are unknown. Therefore, this study was conducted to clarify the significance of endogenous IL10 in the pathogenesis of experimental Graves'
\end{abstract}

disease using IL10 deficient (IL10 ${ }^{-/-}$) mice. Our results show that $\mathrm{T}$ cell response was augmented when estimated by their antigen-specific secretion of the key cytokine IFN $-\gamma$, but $\mathrm{B}$ cell function was dampened, that is, anti-TSHR antibody titers were decreased in IL $10^{-1-}$ mice, resulting in a lower incidence of Graves' hyperthyroidism (54\% in IL $10^{+/+}$vs $25 \%$ in IL $10^{-/-}$). Thus, in addition to IFN- $\gamma$, these data clarified the role of IL10 for optimizing anti-TSHR antibody induction and eliciting Graves' hyperthyroidism in our Graves' mouse model.

Journal of Endocrinology (2011) 209, 353-357

\section{Introduction}

Graves' disease is a thyroid-specific autoimmune disease characterized by overproduction of thyroid hormones and thyroid enlargement by agonistic anti-TSH receptor (TSHR) autoantibody. Graves'-like hyperthyroidism can be experimentally induced in susceptible mouse strains (e.g. $\mathrm{BALB} / \mathrm{c}$ ) by repetitive immunizations with recombinant adenovirus expressing the human full-length TSHR or its A-subunit (Nagayama et al. 2002, Chen et al. 2003). In these models, an in vitro $\mathrm{T}$ cell recall assay demonstrates the antigen-specific secretions of interferon (IFN) $\gamma$ and interleukin (IL) 10 from splenocytes of immunized BALB/c mice (Nagayama et al. 2004b, Saitoh et al. 2007), suggesting the importance of these two cytokines in the disease pathogenesis. Indeed our previous study clearly demonstrates the resistance of IFN- $\gamma$ deficient BALB/c mice to induction of Graves' hyperthyroidism (Nagayama et al. 2004a). This finding indicates that Graves' hyperthyroidism is an autoantibody-dependent but $\mathrm{T}$ helper type 1 (Th1)-mediated autoimmune disease. Our other studies, showing suppression of development of Graves' disease by Th2 polarization induced by parasite infection or IL4, support this notion (Nagayama et al. 2003, 2004b).

Regarding IL10, it was originally discovered as cytokine synthesis inhibitory factor produced by Th2 cells and is now well known to have pleotropic actions on various immune cells (Moore et al. 2001, Asadullah et al. 2003). For example, IL10 has, on the one hand, a regulatory (suppressing) effect on $\mathrm{T}$ cells but, on the other hand, activates $\mathrm{B}$ cells and induces class switching and secretion of antibody. Overall, IL10 is an immunosuppressive cytokine because IL10 deficient $\left(\mathrm{IL} 10^{-/-}\right)$mice spontaneously develop autoimmune diseases (Kuhn et al. 1993). However, the effects of IL10 on autoimmune diseases so far reported vary: exogenous IL10 suppresses (Pennline et al. 1994, Bai et al. 1997, Bettelli et al. 1998, Ma et al. 1998, Batteux et al. 1999) or augments (Ishida et al. 1994, Zhang et al. 2001) and IL10 deficiency inhibits (Poussin et al. 2000, Johansson et al. 2001) or enhances (Poussin et al. 2000, Johansson et al. 2001) different autoimmune diseases. Although we have previously shown that exogenous IL10 prevents BALB/c mice from developing Graves' disease (Saitoh et al. 2005), the consequence of genetic disruption of IL10 gene on this disease has not yet been evaluated in mice.

Therefore, this study was conducted to clarify the significance of endogenous IL10 using IL10 $10^{-/-}$mice. Our data demonstrate that IL10 deficiency dampens induction of Graves' hyperthyroidism by suppressing induction of anti-TSHR antibodies. Thus, in addition to IFN- $\gamma$, IL10 is a cytokine critical for the pathogenesis of Graves' hyperthyroidism in mice. 


\section{Materials and Methods}

Mice

Wild-type (wt) $\mathrm{IL}_{10} 0^{+/+} \mathrm{BALB} / \mathrm{c}$ mice were purchased from Charles River Japan Laboratory, Inc. (Tokyo, Japan) and IL $10^{-/-} \mathrm{BALB} / \mathrm{c}$ mice from Jackson Laboratory, Inc. (Bar Harbor, ME, USA). IL $10^{+/+}$and IL10 $0^{-1-}$ mice were crossed to generate $\mathrm{IL} 10^{+/-}$mice, which were then intercrossed to produce $\mathrm{IL} 10^{+/+}$and $\mathrm{IL} 10^{-/-}$littermate mice. Both males and females were used for the current studies. All the mice were bred in the specific pathogen-free animal facility at Nagasaki University. Animal care and all experimental procedures were performed in accordance with the Guidelines for Animal Experimentation of Nagasaki University with approval of the Institutional Animal Care and Use Committee.

\section{Experimental protocols}

Construction, amplification, purification of non-replicative recombinant human adenovirus expressing the human TSHR A-subunit (Ad-TSHR289), and determination of the viral particle concentration were described previously (Nagayama et al. 2002, Chen et al. 2003).

Mice were i.m injected in the quadriceps with $100 \mu \mathrm{l}$ PBS containing $10^{10}$ particles of Ad-TSHR 289 on two occasions at 3-week intervals. Blood samples and thyroid tissues were obtained 2 weeks after the second immunization.

\section{Thyroxine and anti-TSHR antibody measurements}

Serum-free thyroxine $\left(\mathrm{T}_{4}\right)$ concentrations were measured with a RIA kit (DPC-free $\mathrm{T}_{4}$ kit; Diagnostic Products, Los Angeles, CA, USA) and expressed as ng/dl. The normal range was defined as the mean \pm 3 S.D. of control untreated mice.

Anti-TSHR antibodies in mouse sera were determined by a flow cytometric assay with Chinese hamster ovary cells stably expressing the full-length human TSHR, as described previously (Saitoh et al. 2007). This assay measures the titers of anti-TSHR antibodies recognizing the native TSHR expressed on the cell surface. The data were expressed as percentage mean fluorescent index (MFI) compared with the mean values from control untreated mice. The normal range was defined as the mean \pm 3 S.D. of control mice.

\section{Cytokine assays}

Splenocytes were cultured (triplicate aliquots) at $5 \times 10^{5}$ cells/well in a 96-well round bottomed culture plate in the presence or absence of $10 \mu \mathrm{g} / \mathrm{ml}$ TSHR 289 protein as described previously (Saitoh et al. 2007). The culture supernatants were collected 4 days later. The concentrations of IFN- $\gamma$ and IL10 were determined with Bio-Plex Suspension Array System (Bio-Rad). Cytokine production was expressed as $\mathrm{pg} / \mathrm{ml}$ using a standard curve of recombinant mouse cytokines.

\section{Flow cytometry}

Single-cell suspensions of splenocytes were prepared from spleens, and red cells were lysed in the ammonium chloride buffer. The cells were resuspended in PBS and stained with phycoerythrin or FITC-conjugated anti-CD4 (H129.19), anti-CD8 (53-6.7), anti-CD19 (1D3), anti-CD25 (7D4), anti-CD44 (IM7), and anti-CD62L (MEL-14) (PharMingen, San Diego, CA, USA or eBioscience, San Diego, CA, USA) and analyzed on a FACSCanto II flow cytometry using FACS Diva software (BD Biosciences, San Diego, CA, USA).

\section{Thyroid histology}

Thyroid histology was examined with hematoxylin and eosin (H\&E) staining of formalin-fixed tissue sections.

\section{Statistical analysis}

Levels of $\mathrm{T}_{4}$, anti-TSHR antibodies and cytokines, and incidences of hyperthyroidism were analyzed by $t$-test or by $\chi^{2}$ test respectively. A ' $P$ ' value of $<0 \cdot 05$ was considered statistically significant.
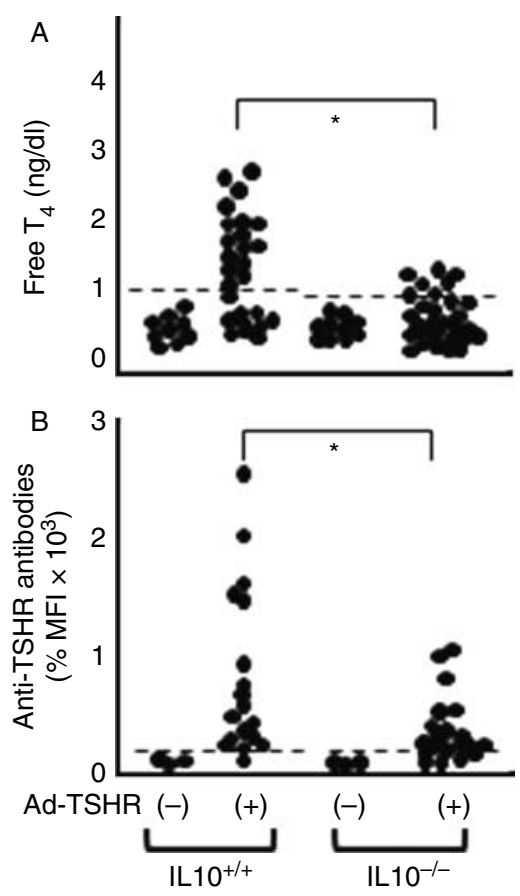

Figure 1 (A) Serum-free $T_{4}$ concentrations and (B) anti-TSHR antibody titers in IL10 $0^{+/+}$and IL $10^{-/-}$BALB/C mice immunized twice with Ad-TSHR289. Free $\mathrm{T}_{4}$ and anti-TSHR antibody levels were determined 2 weeks after the second immunization. Data are shown for individual mice. The horizontal broken lines indicate the normal upper limits of free $T_{4}$ and anti-TSHR antibodies. ND, not determined. 

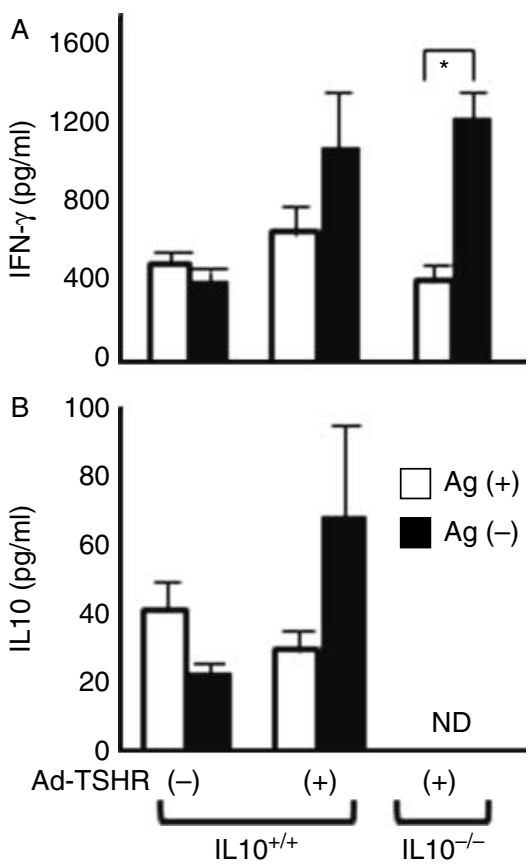

Figure 2 Cytokine production from splenocytes of $\mathrm{IL} 10^{+/+}$and IL10 $10^{-1-}$ BALB/C mice immunized twice with Ad-TSHR289.

Splenocytes were cultured in the presence (solid bars) or absence (open bars) of $10 \mu \mathrm{g} / \mathrm{ml} \mathrm{TSHR} 289$ protein for 4 days. (A) IFN- $\gamma$ and (B) IL10 were measured by Bio-Plex Suspension Array System (see section 'Materials and Methods'). The empty and filled bars indicate IFN- $\gamma$ production in the absence or presence of TSHR289 antigen respectively. The data are means \pm S.E.M. $(n=6) .{ }^{*} P<0 \cdot 05$. ND, not detectable.

\section{Results}

To clarify role(s) played by endogenous IL10 in the pathogenesis of Graves' hyperthyroidism in a mouse model, induction of anti-TSHR immune responses and ensuing development of Graves' hyperthyroidism was compared in the littermates of IL10 $0^{+/+}$and IL10 $0^{-/-}$mice.

As previously reported (Chen et al. 2003), injection of Ad-TSHR289 induced increased $\mathrm{T}_{4}$ in more than half (14 out of $20,53 \cdot 8 \%$ ) of wt $\left(\mathrm{IL}_{10}{ }^{+/+}\right.$) BALB/c mice (Fig. 1A). However, increased $\mathrm{T}_{4}$ was observed only in seven out of 28 (25\%) IL10 $0^{-1-}$ mice. Thus, IL10 deficiency significantly suppressed induction of hyperthyroidism $\left(P<0 \cdot 01\right.$ by $\chi^{2}$ test). Levels of $T_{4}$ were also significantly different between the two groups $\left(1 \cdot 50 \pm 0 \cdot 77\right.$ in IL10 $0^{+/+}$vs $0 \cdot 88 \pm 0 \cdot 35 \mathrm{ng} / \mathrm{dl}$ in IL10 ${ }^{-/-}$mice, mean \pm s.D., $P<0 \cdot 01$ by $t$-test).

Regarding anti-TSHR antibodies (Fig. 1B), the antibody titers were also significantly lower in IL $10^{-1-}$ mice than $\mathrm{IL} 10^{+/+}$mice (MFI; $765 \cdot 7 \pm 774 \cdot 0$ in IL10 $0^{+/+}$vs $331 \cdot 8$ $\pm 344 \cdot 2$ in IL $10^{-/-}$mice, mean \pm s.D., $P<0 \cdot 05$ by $t$-test).

A $\mathrm{T}$ cell recall assay, in which antigen-specific splenocyte secretion of IFN- $\gamma$ in vitro was determined, was then performed as a measure of $\mathrm{T}$ cell activation (Ueki et al. 2011).
In Fig. 2 , in immunized IL10 $0^{+/+}$mice, splenocytes secreted approximately twofold higher amounts of IFN $\gamma$ in response to stimulation with TSHR antigen compared with nonstimulated splenocytes $(1162 \cdot 6 \pm 232 \cdot 3$ in antigen-stimulated splenocytes versus $647 \cdot 5 \pm 142 \cdot 7 \mathrm{pg} / \mathrm{ml}$ in non-stimulated splenocytes, mean \pm s.E.M., $P>0 \cdot 05)$, but this increase is, unlike our previous studies (Nagayama et al. 2003, 2004b, Saitoh \& Nagayama 2006, Saitoh et al. 2007), not statistically significant because of variability of the data. On the other hand, a statistically significantly higher IFN $-\gamma$ secretion was observed in antigen-stimulated splenocytes compared with non-stimulated cells in IL $10^{-/-}$mice $(1215 \cdot 6 \pm 170 \cdot 4$ in antigen-stimulated splenocytes versus $431 \cdot 5 \pm 100 \cdot 9 \mathrm{pg} / \mathrm{ml}$ in non-stimulated splenocytes, mean \pm s.E.M., $P<0 \cdot 05)$. Thus, antigen-specific splenocyte secretion of IFN- $\gamma$ is augmented in IL10 ${ }^{-1-}$ mice. As would be expected, antigen-specific IL10 secretion was observed only in IL10 ${ }^{+/+}$mice (from $29 \cdot 2 \pm 7 \cdot 8$ to $67 \cdot 9 \pm 27 \cdot 4 \mathrm{pg} / \mathrm{ml}$ in immunized IL $10^{+/+}$ mice, mean \pm s.E.M.).

Lymphocyte subsets in spleen were also compared between immunized $\mathrm{IL}_{10} 0^{+/+}$and $\mathrm{IL} 10^{-/-}$mice. In Table 1 , the percentages of $\mathrm{CD} 4{ }^{+} \mathrm{CD} 44^{-} \mathrm{CD} 62 \mathrm{~L}^{+}$naive, $\mathrm{CD} 4{ }^{+} \mathrm{CD} 44^{+} \mathrm{CD}_{22} \mathrm{~L}^{+}$activated, $\mathrm{CD} 4{ }^{+} \mathrm{CD} 44^{+} \mathrm{CD}_{2} \mathrm{~L}^{-}$ memory, and $\mathrm{CD} 4{ }^{+} \mathrm{CD} 25^{+}$regulatory $\mathrm{T}$ cells/CD4 ${ }^{+} \mathrm{T}$ cells and $\mathrm{CD}^{+} \mathrm{T}$ cells were similar between the two groups. However, those of $\mathrm{CD} 4^{+} \mathrm{T}$ cells and $\mathrm{CD} 19^{+} \mathrm{B}$ cells were slightly but significantly lower in IL10 $0^{-1-}$ mice.

Histological examination of $\mathrm{H} \& \mathrm{E}$ staining of the thyroid glands revealed a typical feature for thyroid overstimulation in hyperthyroid mice irrespective of IL10 gene status (data not shown).

\section{Discussion}

Since the first description of Graves' mouse models using recombinant adenovirus expressing the full-length human TSHR in 2002 and the receptor A-subunit in 2003 by our groups (Nagayama et al. 2002, Chen et al. 2003), we have tried to clarify the pathogenesis of this disease using various

Table 1 Comparison of lymphocyte subsets in splenocytes of immunized IL $10^{+/+}$and IL $10^{-/-}$mice

\begin{tabular}{|c|c|c|}
\hline & $\mathrm{IL10}^{+/+}$ & IL10 $^{-/-}$ \\
\hline $\mathrm{CD}^{+}$ & $30 \cdot 7 \pm 2 \cdot 0$ & $21 \cdot 6 \pm 4 \cdot 9 *$ \\
\hline $\mathrm{CD}^{+} \mathrm{CD}_{25}^{+}$ & $6 \cdot 4 \pm 0 \cdot 44$ & $6 \cdot 0 \pm 1 \cdot 45$ \\
\hline $\begin{array}{l}\mathrm{CD} 4{ }^{+} \mathrm{CD} 44^{-} \mathrm{CD} 2 \mathrm{~L}^{+} / \mathrm{CD} 4{ }^{+} \\
\text {naive }\end{array}$ & $6 \cdot 1 \pm 1 \cdot 2$ & $4 \cdot 9 \pm 0 \cdot 8$ \\
\hline $\begin{array}{l}\mathrm{CD} 4{ }^{+} \mathrm{CD} 44^{+} \mathrm{CD}_{2} 2 \mathrm{~L}^{+} / \mathrm{CD} 4{ }^{+} \\
\text {activated }\end{array}$ & $56 \cdot 1 \pm 5 \cdot 3$ & $57 \cdot 1 \pm 5 \cdot 9$ \\
\hline $\begin{array}{l}\mathrm{CD} 4{ }^{+} \mathrm{CD} 44^{+} \mathrm{CD} 2 \mathrm{~L}^{-} / \mathrm{CD} 4{ }^{+} \\
\text {memory }\end{array}$ & $34 \cdot 8 \pm 4 \cdot 6$ & $37 \cdot 9 \pm 3 \cdot 9$ \\
\hline $\mathrm{CD}^{+}$ & $12 \cdot 5 \pm 2 \cdot 1$ & $17 \cdot 0 \pm 4 \cdot 8$ \\
\hline $\mathrm{CD}_{19}^{+}$ & $38 \cdot 3 \pm 5 \cdot 6$ & $29 \cdot 6 \pm 3 \cdot 8^{*}$ \\
\hline
\end{tabular}

*Significantly lower than IL $10^{+/+}$mice $(P<0 \cdot 05$ by $t$-test, $n=3)$. 
approaches. For example, mice genetically deficient for a certain cytokine are useful for this purpose. Indeed the experiments with mice deficient for IFN- $\gamma$ (a Th1 cytokine) or IL17 (a Th17 cytokine) have revealed a critical role played by IFN- $\gamma$, but not IL17, in developing experimental Graves' hyperthyroidism in a susceptible BALB/c mice (Nagayama et al. 2004a, Horie et al. 2010). This study identified IL10 as another important cytokine for the pathogenesis of Graves' disease in mice. Thus, our results show augmented $\mathrm{T}$ cell response when estimated by their antigen-specific secretion of the key cytokine IFN- $\gamma$, but impaired B cell function, that is, decreased anti-TSHR antibody titers, resulting in a lower incidence of Graves' hyperthyroidism, in IL $10^{-/-}$mice.

Since our recent study revealed that not only antibodyproducing but also antigen-presenting abilities of B cells are crucial for development of Graves' hyperthyroidism (Ueki et al. 2011), it is possible that B cell's antigen-presenting ability may also be impaired in IL10 $0^{-/}$mice. Furthermore, lower percentage of $\mathrm{CD} 19^{+} \mathrm{B}$ cells in $\mathrm{IL} 10^{-/-}$mice is likely attributed to lack of positive regulation by IL10.

These results are generally consistent with previous studies showing that $\mathrm{T}$ cells from IL $10^{-/-}$mice exhibit enhanced antigen-specific response probably due to lack of the regulatory function of IL10 on $\mathrm{T}$ cells, but B cells from IL10 ${ }^{-/-}$mice show impaired function due to lack of IL10's ability to stimulate B cells (Bettelli et al. 1998, Poussin et al. 2000).

In the previous studies, exogenous IL10 administration or transgenic/gene transfer-mediated IL10 overexpression suppresses cell-mediated autoimmune diseases such as autoimmune neuritis (Bai et al. 1997), collagen-induced arthritis (Ma et al. 1998), experimental autoimmune encephalitis (EAE; Bettelli et al. 1998), diabetes (Pennline et al. 1994), and Hashimoto's thyroiditis (Batteux et al. 1999), but enhances antibody-mediated disease including lupus (Ishida et al. 1994) and myasthenia gravis (Zhang et al. 2001). On the other hand, IL10 ${ }^{-/-}$mice are more susceptible to EAE (Bettelli et al. 1998) and collagen-induced arthritis (Johansson et al. 2001), but resistant to myasthenia gravis (Poussin et al. 2000) and anti-type II collagen antibody-induced arthritis (Johansson et al. 2001). Thus IL10 appears to suppress cell-mediated autoimmune diseases but to accelerate antibody-mediated autoimmune diseases (not necessarily Th2 diseases) including Graves' disease. In other words, the regulatory function of IL10 on T cells likely dominates over its stimulatory function on B cells in cell-mediated autoimmune diseases, while IL10's stimulatory ability to B cells appears to be dominant in antibody-mediated autoimmune diseases.

However, a difference between our data and the others is that not only IL10 gene disruption (this study) but also gene transfer-mediated IL10 overexpression (Saitoh et al. 2005) has also suppressed Graves' hyperthyroidism in our mouse Graves' model. Although the reason(s) for this difference is unclear, it is not surprising that the pharmacological levels of exogenous IL10 and the physiological levels of endogenous
IL10 have distinct functions, as we have previously shown for IL4 (Nagayama et al. 2003, 2004a).

Overexpression of IL10 has recently been shown to induce $\mathrm{CD} 4{ }^{+} \mathrm{CD} 25^{+}$regulatory $\mathrm{T}$ cells (Goudy et al. 2003), which are well known to negatively regulate immune response (Sakaguchi 2005). Indeed our recent antibody-mediated depletion study has demonstrated a regulatory role of CD $4{ }^{+} \mathrm{CD} 25^{+} \mathrm{T}$ cells in Graves' hyperthyroidism (Saitoh \& Nagayama 2006). Although the percentages of $\mathrm{CD} 4{ }^{+} \mathrm{CD} 25^{+}$regulatory $\mathrm{T}$ cells have not been studied in our previous report (Saitoh et al. 2005) and they were the same between IL $10^{+/+}$and IL $10^{-/-}$mice in this study, the effect of IL10 deficiency on T cell's regulatory function may be worth scrutinizing.

Overall, this study, together with our previous study (Nagayama et al. 2004a), identified IFN- $\gamma$ and IL10 as critical cytokines for inducing anti-TSHR antibodies and eliciting Graves' hyperthyroidism in our mouse model. It may be worth noting here that, clinically, the role of IL10 for the pathogenesis of Graves' disease can also be suspected by studies on IL10 gene polymorphisms (Khalilzadeh et al. 2010) and on serum IL10 concentrations in patients with autoimmune thyroid diseases (Takeoka et al. 2004).

\section{Declaration of interest}

The authors declare that there is no conflict of interest that could be perceived as prejudicing the impartiality of the research reported.

\section{Funding}

This study was supported by Grant-in-Aid for Scientific Research and Global COE Program from the Ministry of Education, Culture, Sports, Science and Technology of Japan.

\section{Author contribution statement}

$\mathrm{Y} N$ conceived and designed the experiments, and wrote the manuscript; and I U, N A, and K K performed the experiments and analyzed the data.

\section{References}

Asadullah K, Sterry W \& Volk HD 2003 Interleukin-10 therapy - review of a new approach. Pharmacological Reviews 55 241-269. (doi:10.1124/pr.55.2.4)

Bai XF, Zhu J, Zhang GX, Kaponides G, Hojeberg B, van der Meide PH \& Link H 1997 IL-10 suppresses experimental autoimmune neuritis and down-regulates TH1-type immune responses. Clinical Immunology and Immunopathology 83 117-126. (doi:10.1006/clin.1997.4331)

Batteux F, Trebeden H, Charreire J \& Chiocchia G 1999 Curative treatment of experimental autoimmune thyroiditis by in vivo administration of plasmid DNA coding for interleukin-10. European Journal of Immunology 29 958-963. (doi:10.1002/(SICI)1521-4141(199903)29:03<958::AIDIMMU958>3.0.CO;2-D)

Bettelli E, Das MP, Howard ED, Weiner HL, Sobel RA \& Kuchroo VK 1998 IL-10 is critical in the regulation of autoimmune encephalomyelitis as demonstrated by studies of IL-10- and IL-4-deficient and transgenic mice. Journal of Immunology 161 3299-3306. 
Chen CR, Pichurin P, Nagayama Y, Latrofa F, Rapoport B \& McLachlan SM 2003 The thyrotropin receptor autoantigen in Graves disease is the culprit as well as the victim. Journal of Clinical Investigation 111 1897-1904. (doi:10.1172/JCI17069)

Goudy KS, Burkhardt BR, Wasserfall C, Song S, Campbell-Thompson ML, Brusko T, Powers MA, Clare-Salzler MJ, Sobel ES, Ellis TM et al. 2003 Systemic overexpression of IL-10 induces CD4 + CD25 + cell populations in vivo and ameliorates type 1 diabetes in nonobese diabetic mice in a dose-dependent fashion. Journal of Immunology 171 2270-2278.

Horie I, Abiru N, Saitoh O, Ichikawa T, Iwakura Y, Eguchi K \& Nagayama Y 2010 Distinct role of T helper Type 17 immune response for Graves' hyperthyroidism in mice with different genetic backgrounds. Autoimmunity 44 159-165. (doi:10.3109/08916931003777247)

Ishida H, Muchamuel T, Sakaguchi S, Andrade S, Menon S \& Howard M 1994 Continuous administration of anti-interleukin 10 antibodies delays onset of autoimmunity in NZB/W F1 mice. Journal of Experimental Medicine 179 305-310. (doi:10.1084/jem.179.1.305)

Johansson AC, Hansson AS, Nandakumar KS, Backlund J \& Holmdahl R 2001 IL-10-deficient B10.Q mice develop more severe collagen-induced arthritis, but are protected from arthritis induced with anti-type II collagen antibodies. Journal of Immunology 167 3505-3512.

Khalilzadeh O, Anvari M, Momen-Heravi F, Esteghamati A, Rashidi A, Mahmoudi M, Nikbin B \& Amirzargar A 2010 Gene polymorphisms of interleukin-4, interleukin-10 and transforming growth factor-beta in Graves' disease. Clinical and Experimental Medicine 10 123-128. (doi:10. 1007/s10238-009-0078-5)

Kuhn R, Lohler J, Rennick D, Rajewsky K \& Muller W 1993 Interleukin10-deficient mice develop chronic enterocolitis. Cell 75 263-274. (doi:10. 1016/0092-8674(93)80068-P)

Ma Y, Thornton S, Duwel LE, Boivin GP, Giannini EH, Leiden JM, Bluestone JA \& Hirsch R 1998 Inhibition of collagen-induced arthritis in mice by viral IL-10 gene transfer. Journal of Immunology 161 1516-1524.

Moore KW, de Waal Malefyt R, Coffman RL \& O'Garra A 2001 Interleukin-10 and the interleukin-10 receptor. Annual Review of Immunology 19 683-765. (doi:10.1146/annurev.immunol.19.1.683)

Nagayama Y, Kita-Furuyama M, Ando T, Nakao K, Mizuguchi H, Hayakawa T, Eguchi K \& Niwa M 2002 A novel murine model of Graves' hyperthyroidism with intramuscular injection of adenovirus expressing the thyrotropin receptor. Journal of Immunology 168 2789-2794.

Nagayama Y, Mizuguchi H, Hayakawa T, Niwa M, McLachlan SM \& Rapoport B 2003 Prevention of autoantibody-mediated Graves'-like hyperthyroidism in mice with IL-4, a Th2 cytokine. Journal of Immunology 170 3522-3527.

Nagayama Y, Saitoh O, McLachlan SM, Rapoport B, Kano H \& Kumazawa Y $2004 a$ TSH receptor-adenovirus-induced Graves' hyperthyroidism is attenuated in both interferon-gamma and interleukin-4 knockout mice; implications for the Th1/Th2 paradigm. Clinical and Experimental Immunology 138 417-422. (doi:10.1111/j.1365-2249.2004.02641.x)
Nagayama Y, Watanabe K, Niwa M, McLachlan SM \& Rapoport B $2004 b$ Schistosoma mansoni and alpha-galactosylceramide: prophylactic effect of Th1 immune suppression in a mouse model of Graves' hyperthyroidism. Journal of Immunology 173 2167-2173.

Pennline KJ, Roque-Gaffney E \& Monahan M 1994 Recombinant human IL-10 prevents the onset of diabetes in the nonobese diabetic mouse. Clinical Immunology and Immunopathology 71 169-175. (doi:10.1006/clin. 1994.1068)

Poussin MA, Goluszko E, Hughes TK, Duchicella SI \& Christadoss P 2000 Suppression of experimental autoimmune myasthenia gravis in IL-10 genedisrupted mice is associated with reduced $\mathrm{B}$ cells and serum cytotoxicity on mouse cell line expressing AChR. Journal of Neuroimmunology 111 152-160. (doi:10.1016/S0165-5728(00)00385-4)

Saitoh O \& Nagayama Y 2006 Regulation of Graves' hyperthyroidism with naturally occurring $\mathrm{CD} 4{ }^{+} \mathrm{CD} 25^{+}$regulatory $\mathrm{T}$ cells in a mouse model. Endocrinology 147 2417-2422. (doi:10.1210/en.2005-1024)

Saitoh O, Mizutori Y, Takamura N, Yamasaki H, Kita A, Kuwahara H \& Nagayama Y 2005 Adenovirus-mediated gene delivery of interleukin-10, but not transforming growth factor beta, ameliorates the induction of Graves' hyperthyroidism in BALB/c mice. Clinical and Experimental Immunology 141 405-411. (doi:10.1111/j.1365-2249.2005.02874.x)

Saitoh O, Abiru N, Nakahara M \& Nagayama Y 2007 CD8 ${ }^{+}$CD $122^{+}$T cells, a newly identified regulatory $\mathrm{T}$ subset, negatively regulate Graves' hyperthyroidism in a murine model. Endocrinology 148 6040-6046. (doi:10. 1210/en.2007-0300)

Sakaguchi S 2005 Naturally arising Foxp3-expressing CD $25^{+} \mathrm{CD} 4^{+}$ regulatory $\mathrm{T}$ cells in immunological tolerance to self and non-self. Nature Immunology 6 345-352. (doi:10.1038/ni1178)

Takeoka K, Watanabe M, Matsuzuka F, Miyauchi A \& Iwatani Y 2004 Increase of serum interleukin-10 in intractable Graves' disease. Thyroid 14 201-205. (doi:10.1089/105072504773297876)

Ueki I, Abiru N, Kobayashi M, Nakahara M, Ichikawa T, Eguchi K \& Nagayama Y 2011 B cell-targeted therapy with anti-CD20 monoclonal antibody in a mouse model of Graves' hyperthyroidism. Clinical and Experimental Immunology 163 309-317. (doi:10.1111/j.1365-2249.2010. 04301.x)

Zhang GX, Xiao BG, Yu LY, van der Meide PH \& Link H 2001 Interleukin 10 aggravates experimental autoimmune myasthenia gravis through inducing Th2 and B cell responses to AChR. Journal of Neuroimmunology 113 10-18. (doi:10.1016/S0165-5728(00)00411-2)

Received in final form 6 April 2011

Accepted 7 April 2011

Made available online as an Accepted Preprint 7 April 2011 